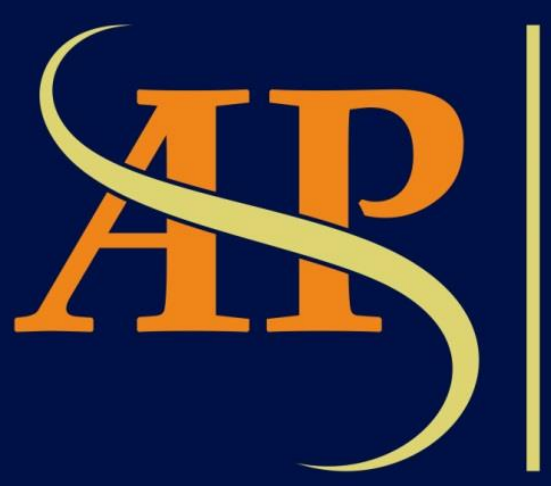

JURNAL

ASIA

PACIFIC

STUDIES

Journal of International Relations Study Program Faculty of Social and Political Sciences

Universitas Kristen Indonesia

Volume 4| Number 1 | January- June 2020 


\title{
Analisis Kebijakan Luar Negeri John Howard Terhadap Imigran Ilegal di Australia
}

\author{
${ }^{1}$ Dhea T. Lumentut, ${ }^{2}$ Yan G. Pelamonia, ${ }^{3}$ Johni R.V. Korwa \\ ${ }^{1,2,3}$ Program Studi Hubungan Internasional, Fakultas Ilmu Sosial dan Ilmu Politik, Universitas Cenderawasih, \\ Jl. Uncen, Yabansai, Heram, Kota Jayapura, Papua 99224 \\ ${ }^{1}$ tallytadhea@gmail.com, ${ }^{2}$ yangilbert755@gmail.com, 3 korwajohni@yahoo.com
}

\begin{abstract}
This paper aims to analyze Australian Prime Minister John Howard's foreign policy in responding to illegal immigrants who attempt to enter Australian territory by sea. This study employed library research as well as a qualitative approach. In particular, this study used the theory of foreign policy offered by Walter Carlsnaes called 'a logically tripartite approach' to analyze Howard's policy in responding to illegal immigrants. This paper found that Howard's foreign policy in responding to illegal immigrants was not only state-centric in nature focusing on protecting Australian sovereignty, but the policy also had a purpose to maintain power control. Firstly, Howard was willing to show the world that his leadership was different compared to his predecessors, asserting that Australia should not be regarded as a country of easy destination. Secondly, Howard showed that limiting the number of illegal immigrants was in the best interest of the country to protect Australians. Thirdly, Howard proved that his foreign policy towards illegal immigrants could influence the politics of Australia including federal elections. Lastly, Howard demonstrated his ability in the context of institutional setting by issuing new laws to strengthen his foreign policy.
\end{abstract}

Keywords: Australi, John Howard, Illegal Immigrants, Policy

\begin{abstract}
Abstrak
Tulisan ini bertujuan untuk menganalisis kebijakan luar negeri Perdana Menteri John Howard dalam merespon para imigran ilegal yang datang ke Australia secara khusus melalui jalur laut. Studi ini menggunakan metode studi pustaka dan pendekatan kualitatif. Secara khusus, penulis menggunakan teori kebijakan luar negeri yang ditawarkan oleh Walter Carlsnaes yang disebut 'a logically tripartite approach' untuk menganalisis kebijakan Howard dalam merespon imigran ilegal. Studi ini menemukan bahwa kebijakan luar negeri Howard dalam merespon imigran ilegal tidak hanya bersifat state-centric yang berfokus pada perlindungan kedaulatan negara, tetapi kebijakan itu juga memiliki motivasi untuk mempertahankan kekuasaan. Pertama, Howard ingin menunjukkan pada dunia bahwa ia adalah pemimpin yang berbeda dari pendahulunya dengan menegaskan bahwa Australia seharusnya tidak dipertimbangkan sebagai negara yang dapat dicapai dengan mudah. Kedua, Howard ingin menunjukkan bahwa pembatasan jumlah imigran ilegal adalah capaian kepentingan nasional untuk melindungi komunitas Australia. Ketiga, Howard menunjukkan bahwa kebijakannya terkait imigran ilegal dapat memengaruhi nuansa perpolitikan di Australia khususnya pada pemilihan umum federal. Keempat, Howard menunjukkan kemampuannya dalam konteks pengelolaan kelembagaan dengan mengeluarkan Undang-Undang baru hasil amandemen untuk memperkuat kebijakan luar negerinya.
\end{abstract}

Kata kunci: Australia, John Howard, Imigran Ilegal, Kebijakan 


\section{Pendahuluan}

Isu pencari suaka (asylum seekers) merupakan sebuah fenomena global yang sering terjadi di berbagai negara termasuk di Australia. Upaya pencari suaka untuk sampai ke wilayah Australia dapat dilakukan dengan berbagai cara termasuk dengan menggunakan kapal secara tidak teratur, yang dikenal dengan istilah 'Irregular Maritime Arrivals' (IMAs). Australia merupakan sebuah negara dan benua yang secara geografis berada di antara Samudera Hindia dan Samudera Pasifik sehingga posisi ini menjadi jalur masuk yang ideal bagi para pencari suaka. Selain itu, Australia juga banyak diminati karena termasuk dalam cluster negara kaya (developed countries) dan tempat berkumpulnya kelompok etnik dari berbagai dunia (multicultural), sehingga membuat para pencari suaka akan mudah dalam beradaptasi ketika aplikasi mereka berhasil diterima sebagai pengungsi (refugees). Australia sendiri tercatat sebagai salah satu dari 145 negara dunia yang telah menandatangani Konvensi 1951 dan Teks Protokol 1967 Mengenai Status Pengungsi (Taylor 2005, 1).

Salah satu contoh event besar dalam sejarah Australia terkait pencari suaka adalah kasus 'Tampa Affair' pada Agustus 2001. Tampa adalah kapal ferry pengangkut yang berasal dari Norwegia. Kasus ini menjadi unik karena Perdana Menteri John Howard ketika itu menggunakan tindakan militer untuk mencegah kapal tersebut masuk perairan Australia. Kapal pengangkut ini membawa sekitar 438 pencari suaka yang mayoritas berasal dari Afghanistan, ditambah dengan beberapa orang Pakistan dan Sri Lanka. Mereka awalnya menggunakan kapal kayu, namun tenggelam sekitar 75 mil dari Pulau Christmas (Australia) dan 246 mil dari pelabuhan Indonesia sehingga mereka mengirim alarm bahaya dan direspon oleh kapal Tampa (Philpott 2002, 63). John Howard kemudian secara tegas memberi larangan kepada kapten Tampa agar tidak memasuki wilayah perairan Australia. Howard melihat bahwa Australia seakan dianggap oleh pencari suaka sebagai negara yang mudah untuk dimasuki, seperti dalam interview-nya dengan Sydney Morning Herald, "We simply cannot allow a situation to develop where Australia is seen around the world as a country of easy destination..."(Kelly 2009, 552).

Meskipun kapten Tampa -Arne Rinnan- mematuhi larangan Howard untuk tidak memasuki perairan Australia, berselang dua hari kemudian beberapa pengungsi mengeluh terkait masalah kesehatan sehingga kapten kapal akhirnya membawa mereka menuju daratan Australia. Sebagai respon, John Howard memerintahkan pasukan militer terlatih untuk menaiki kapal Tampa dan mencegah agar tidak menuju wilayah Australia (Fox 2010, 357). Howard mayakini bahwa dia harus melindungi kepentingan nasional Australia dengan membatasi jumlah imigran ilegal yang masuk ke negaranya, "... I believe it is in Australia's national interests that we draw a line on what is increasingly becoming an uncontrollable number of illegal arrivals in this country (Menjívar et al., 2019, 525). Namun pencegahan Howard tersebut dianggap tidak fair karena sebelas hari sebelum Kapal Tampa menuju daratan Australia, beberapa perahu kecil berisi sekitar 1.500 pencari suaka ternyata telah menuju daratan Australia terlebih dahulu (Pipes, 2001). Howard menolak kapal Tampa karena menganggap para pencari suaka tersebut sebagai 'Irregular Maritime Arrivals' yang memberi ancaman terhadap keamanan negaranya. Pencari suaka yang menggunakan perahu dengan dokumen perjalanan yang tidak sah untuk memasuki wilayah sebuah negara dapat dikategorikan sebagai 'undocumented migration' atau 'illegal migration'. Dalam studi ini, penulis menggunakan istilah 'imigran ilegal' untuk menggambarkan pencari suaka tersebut.

Tulisan ini bertujuan untuk menganalisis kebijakan luar negeri Perdana Menteri John Howard dalam merespon para imigran ilegal yang datang ke Australia secara khusus melalui jalur laut. Topik ini menjadi penting karena studi kasus di Australia (Tampa Affair) dapat menjadi pelajaran penting (lesson learned) bagi dunia saat ini, khususnya negara-negara yang telah menandatangani Konvensi pengungsi, agar menjadi lebih baik dan bijak dalam 
merespon imigran illegal. Struktur penulisan terbagi ke dalam beberapa bagian. Pertama, penulis akan menjelaskan metodologi yang digunakan termasuk penjabaran mengenai 'theory of foreign policy' yang dikembangkan oleh Walter Carlsnaes. Kedua, penulis akan masuk dalam ruang pembahasan dengan fokus pada isu pencari suaka dalam paradigma pemerintahan PM John Howard; kecaman internasional terhadap Kebijakan Howard; Kebijakan Howard dalam membatasi arus pencari suaka dan pengungsi; dan Kebijakan Luar Negeri Howard berdasarkan 'a logically tripartite approach'. Ketiga, penulis akan memberi kesimpulan dari hasil dan diskusi.

\section{Studi Literatur}

Adapun teori yang penulis gunakan dalam studi ini adalah teori kebijakan luar negeri atau 'theory of foreign policy'. Holsti (1992:21) mengatakan bahwa lingkup kebijakan luar negeri meliputi semua tindakan serta aktivitas negara terhadap lingkungan eksternalnya dalam upaya memperoleh keuntungan dari lingkungan tersebut, serta hirau akan berbagai kondisi internal yang menopang formulasi tindakan tersebut. Ada empat hal yang menjadi tujuan utama dari Foreign Policy yaitu, 1) security atau keamanan; 2) otonomi; 3) kesejahteraan; 4) status atau prestige. Encyclopaedia Britannica (2020) menjabarkan tiga faktor yang sering memengaruhi pengembangan kebijakan luar negeri yaitu: pertimbangan domestik (domestic considerations); kebijakan atau perilaku negara lain (the policies or behaviour of other states); dan rencana untuk memajukan desain geopolitik tertentu (plans to advance specific geopolitical designs). Sementara itu, Carlsnaes (1992:254) mengusulkan tiga dimensi yang saling berhubungan dan dapat digunakan untuk menjelaskan tindakan terkait pengambilan kebijakan luar negeri yang ia sebut 'a logically tripartite approach'. Pertama adalah Intentional Dimension yang terdiri atas pilihan (choice) dan preferensi (preference). Kedua adalah Dispositional Dimension yang terdiri atas persepsi (perceptions) dan nilai (values). Ketiga adalah Structural Dimension yang terdiri atas kondisi obyektif (objective conditions) dan pengaturan kelembagaan (institutional setting). Dari penjelasan di atas, penulis memilih untuk menggunakan pendekatan Carlsnaes dalam menganalisis kebijakan luar negeri Howard merespon imigran ilegal.

\section{Metode Penelitian}

Penulis menggunakan pendekatan kualitatif untuk menggambarkan dan menganalisis kebijakan luar negeri Howard dalam kaitannya dengan imigran ilegal. Teknik pengumpulan data yang digunakan adalah studi pustaka (library research) yang sumbernya berasal dari jurnal, buku, website resmi pemerintah, dan data sekunder lainnya.

\section{Hasil dan Diskusi}

Isu pencari suaka memiliki pengaruh besar dalam konteks kemanusiaan. Seperti yang dikatakan sebelumnya bahwa Australia merupakan salah satu negara yang telah menandatangani Konvensi 1951 dan Teks Protokol 1967 Mengenai Status Pengungsi. Artinya bahwa Australia harus bertanggung jawab dalam menerima dan memberikan kehidupan yang lebih baik bagi para pencari suaka yang berpotensi sebagai pengungsi Australia (Prabaningtyas 2015, 70; Creek 2014, 479). Namun dalam kasus Tampa, pemerintah Australia terkesan sangat berhati-hati dalam menerima para pencari suaka dan bahkan penolakan pun 
terjadi. Tindakan ini tentunya dipengaruhi oleh style kepemimpinan pada era tersebut, yaitu pada masa pemerintahan PM John Howard.

\subsection{Isu Pencari Suaka dalam Paradigma Pemerintahan PM John Howard}

Intensitas jumlah pencari suaka di Australia merupakan faktor pendorong mengapa Perdana Menteri John Howard memformulasikan kebijakan luar negeri yang kuat untuk merespon hal tersebut. Kebijakan tersebut diambil agar jumlah populasi dari para pencari suaka yang masuk ke Australia tidak mengalami peningkatan yang signifikan. Hal itu dapat mengakibatkan ketidakseimbangan keamanan negara karena para pencari suaka yang masuk ke Australia berasal dari berbagai latar belakang kehidupan, dan karena itu, mungkin saja beberapa dari mereka adalah teroris atau pelaku kejahatan lainnya yang menyamar sebagai pencari suaka. Selain itu, tindakan yang diambil oleh Howard juga merupakan wujud visi dan misi Australia untuk mencegah dan menjaga keamanan lingkungan yang berhubungan dengan kepentingan nasional. Menurut Bhakti, dikutip dalam Puteri (2011:8-9), faktor-faktor internal yang memengaruhi kebijakan luar negeri Australia antara lain adalah faktor sejarah dan demografis, kepentingan nasional, cara pandang aktor politik (pemberi pengaruh, pembuat dan penentu kebijakan) terhadap sistem internasional, serta kepentingan dan peran yang diinginkan oleh negara tersebut di dalam sistem internasional.

Di sisi lain, Howard juga memiliki kepentingan politik pribadi, yaitu agar masyarakat melihatnya sebagai pemimpin yang bijak dalam menangani permasalahan yang terjadi di dalam negaranya. Itu adalah cara Howard untuk mempertahankan kedudukan dan reputasinya sebagai perdana menteri Australia. Hal ini berkaitan juga dengan pendekatan politik yang disebut 'populisme'. Populisme, menurut Savirani et al., dikutip dalam Septa (2018:9), merupakan alternatif dari patronase. Pada konsep patronase, seorang aktor dalam sebuah negara akan menggunakan pemberdayaan kekuatan ekonomi dan kekuatan sosialnya untuk semakin memperkuat hubungan antara penguasa dan publik. Sedangkan dalam populisme, seorang elit politik akan menggunakan program-program yang digagas sebagai sarana untuk menarik perhatian publik dengan harapan dapat mengkonversikannya menjadi dukungan bagi elit politik tersebut. Kebijakan politik luar negeri pada masa pemerintahan Perdana Menteri Howard yang berhubungan dengan imigran ilegal memberikan dampak yang begitu besar bagi masyarakat Australia. Hal itu seakan-akan mendoktrin masyarakat agar ikut menolak masuknya pencari suaka dan para pengungsi ke wilayah Australia. Dengan demikian kebijakan yang dibuat Howard tersebut mendapat dukungan dan disetujui oleh masyarakat. Pengaruh besar Howard juga mampu membuat masyarakat Australia melakukan aksi-aksi penolakan terhadap gelombang imigran.

\subsection{Kecaman Internasional Terhadap Kebijakan PM John Howard}

Dalam persepektif internasional, kebijakan luar negeri yang dikeluarkan oleh Howard dinilai tidak begitu baik untuk menyelesaikan kasus imigran ilegal yang ingin mencari kehidupan baru di Australia. Hal ini atas dasar kemanusiaan yaitu tindakan yang diberlakukan kepada para imigran tersebut tidak sesuai dengan norma kemanusiaan yang telah berlaku. Kebijakan itu dianggap menyimpang dari hasil perjanjian yang telah ditetapkan dalam konvensi Jenewa tentang perlindungan kepada (calon) pengungsi. Kebijakan Australia di bawah Pemerintahan Howard dalam menolak imigran ilegal ternyata menuai kecaman dan respon dari komunitas internasional. Seperti yang disampaikan oleh Komisaris HAM PBB Mary Anderson bahwa pemerintah federal Australia seharusnya mempertimbangkan aksi pertolongan terhadap para imigran ilegal dalam kondisi darurat karena hal tersebut merupakan tanggung jawab sebuah negara yang telah menandatangani Konvensi Pengungsi. Hal ini juga 
dikatakan oleh United Nations High Commissioner for Refugees (UNHCR) bahwa para imigran ilegal sudah seharusnya diterima oleh semua negara yang tergabung dalam konvensi pengungsi, termasuk Australia. Australia tidak hanya terlibat dalam beberapa konvensi internasional tapi juga protokol yang dikeluarkan guna memberikan perlindungan terhadap hak para calon pengungsi (Septa 2018, 3-4).

Namun, fakta menunjukkan bahwa para imigran ilegal mendapatkan perlakuan yang kurang begitu baik bahkan mendapat penolakan dari pemerintah federal Australia. Jika ditinjau dari asas hukum internasional, tentu saja ini dinilai sebagai pelanggaran terhadap asas Non-Refoulement, Non-Expulsion, Rejection at the Frontiers, dan Asylee (Riyanto 2010, 434). Pemerintah Howard sudah seharusnya menyelamatkan para imigran ilegal tersebut tanpa mempertimbangkan dari negara mana mereka berasal, apa ras dan agama mereka, seperti yang dikatakan dalam pasal 33 ayat 1 Konvensi 1951 Terkait Status Pengungsi, 'No contracting state shall expel or return ("refouler") a refugee in any manner whatsoever to the frontiers of territories where his life or freedom would be threatened on account of his race, religion, nationality, membership of a particular social group or political opinion' (Nurcahyawan dan Andika 2017, 6).

\subsection{Kebijakan PM John Howard dalam Membatasi Arus Pencari Suaka dan Pengungsi}

Pemerintahan Australia di bawah kepemimpinan John Howard banyak menghadapi pro dan kontra dari berbagai kalangan atas tindakan dan upaya dalam mengurangi arus imigran ilegal yang berdatangan untuk mencari kehidupan baru di negaranya. Hal tersebut membuat adanya perombakan legislasi pada awal pemerintahannya, di mana perubahan itu mengarah pada pembatasan arus pengungsi. Ada empat Undang-Undang (UU) baru yang berhubungan dengan imigrasi pada masa pemerintahan Howard, yaitu:

\subsubsection{Migration Legislation Amendment Act No 6. 2001 (MLA Act)}

Undang-undang ini mempersempit interpretasi yang diberikan pada terminologi 'pengungsi' (khususnya unsur-unsur penganiayaan, keanggotaan suatu kelompok sosial tertentu dan kejahatan sangat serius) serta membatasi pemberian status ekstensi dari seorang ayah/ibu kepada anaknya, dan sebaliknya dalam konteks pengungsi. Secara khusus, UU ini bersifat ketat kepada para pengungsi yang sudah bermukim di Australia. Artinya bahwa apabila seseorang sudah berstatus sebagai pengungsi, maka tidak dapat membawa keluarga lainnya untuk tinggal bersama-sama dengannya di Australia (Villar 2001). Undang-undang ini juga sangat menekankan bagi para pengungsi yang ingin datang dan tinggal di Australia untuk tidak boleh mempunyai status kriminal di negaranya (termasuk perusakan properti/nonpolitis), karena akan dianggap sebagai ancaman dan selanjutnya akan dipulangkan ke negara asal (repatriasi). Namun, jika dicermati dengan seksama, UU ini sebenarnya bertolak belakang dengan prinsip Non-Refoulement pada pasal 33 Ayat 1 dalam Konvensi 1951 yang menolak pengembalian pengungsi ke negara asalnya (Azis 2014, 88)..

\subsubsection{Borders Protection (Validation and Enforcement Powers) Act, 2001 (BPB Act)}

Undang-undang ini sebagai landasan bagi para officer (Australian Defence Force) termasuk militer Angkatan Laut yang bertugas menjaga perairan Australia dalam membatasi kapal-kapal atau perahu yang berisikan imigran 'ilegal'. Para officer diberikan kuasa untuk melakukan tindakan koersif (seperti penggeledahan dan strip-searches) di atas kapal atau perahu yang membawa para imigran 'ilegal'. Apabila dalam penggeledahan dan pemeriksaan 
tersebut terbukti ada yang tidak memenuhi persyaratan, maka para imigran 'ilegal' tersebut tidak dapat mengurus visa. Hal ini sesuai dengan tindakan-tindakan di bawah BPB Act (Azis 2014, 89). Poin utama dari UU ini adalah memberikan power kepada para officer untuk melakukan tindakan paksaan kepada imigran ilegal, dan tindakan tersebut selanjutnya dianggap tidak melanggar hukum dan tidak dapat dituntut di pengadilan. Seperti yang dikatakan pada Subsection 185(3A): "If an officer detains a ship or aircraft under this section, any restraint on the liberty of any person found on the ship or aircraft that results from the detention of the ship or aircraft is not unlawful, and proceedings, whether civil or criminal, in respect of that restraint may not be instituted or continued in any court against the Commonwealth, the officer or any person assisting the officer in detaining the ship or aircraft" (Australian Government 2001).

\subsubsection{Migration Amendment (Excision from migration zone) Act 2001 (MAB Act)}

UU ini dengan jelas menyatakan bahwa beberapa wilayah eksternal Australia (Christmas Island, Ashmore and Cartier Islands, and Cocos (Keeling) Islands) yang mudah dicapai pengungsi onshore dihapuskan (excised) statusnya sebagai zona migrasi, selanjutnya dikenal dengan istilah 'excised offshore places'. Sebagai konsekuensinya, para pengungsi yang mencapai wilayah yang telah dihapuskan tersebut tidak dapat mengajukan aplikasi visa pada pemerintah federal Australia (Azis 2014, 89). Regulasi ini ternyata hanya berlaku dalam konteks hukum domestik Australia saja; tidak untuk hukum internasional yang mengikat Australia di bawah payung pengungsi. Konsekuensinya adalah UU tersebut menimbulkan inkonsistensi kebijakan dari interpretasi hukum internasional yang diadopsi Australia untuk menjadi regulasi nasional dalam konteks pengungsi. UU ini juga ternyata mendapat kritikan yang dikaitkan dengan masalah territorial sovereignty, di mana penghapusan beberapa wilayah eksternal tersebut akan menciptakan masalah pada status kedaulatan Australia. Seperti dikatakan oleh salah satu komentator yang dikutip dalam Coombs (2004), "It could well be argued where parts of Australian sovereignty over certain islands is a bit fragile in the sense it could be subject to being tested, this in the long run is not good policy or legal practice. The types of processes we're talking about here just lead to an impression of Australian disinterest in those islands and those territories".

\subsubsection{Migration Amendment (Excision from migration zone) (Consequential Provision) Act 2001 (MAB II Act)}

Undang-undang ini memliki dua tujuan, yaitu 1) mengamandemen UU Migrasi 1958 untuk mengklarifikasi kekuasaan dan kewajiban yang berkaitan dengan penahanan dan perpindahan orang yang tiba secara tidak sah di tempat-tempat tertentu yang dikeluarkan dari wilayah Australia untuk keperluan Undang-Undang Migrasi 1958; dan 2) mengamandemen Regulasi Migrasi 1994 untuk menciptakan kelas baru pengungsi dan visa kemanusiaan untuk berurusan dengan pergerakan sementara orang yang mencari suaka (Spooner dan Hancocok 2001). Dalam praktiknya, UU ini juga memberikan kuasa penuh kepada para militer untuk menahan warga yang bukan berasal dari Australia yang dicurigai secara ilegal telah memasuki teritori Australia seperti yang dijabarkan dalam MAB Act. Apabila pengungsi onshore telah mencapai excised offshore places maka mereka tidak mempunyai hak dalam mengajukan diri sebagai pencari suaka di daratan Australia. Undang-undang ini juga mengatur bahwa para pencari suaka tidak langsung dibawa ke Australia dalam pengurusan statusnya, namun mereka digiring ke tempat offshore detention centres sebagai tempat penahanan para pengungsi "ilegal". Berdasarkan Australia MAB II Act, Australia dimungkinkan untuk menunjuk negara lain "Declared Country" (Nauru and PNG) guna penahanan imigran ilegal. Dengan 
diberlakukannya UU ini, para pengungsi juga tidak dapat menuntut pemerintah Australia di pengadilan (Azis 2014, 89). Follow up dari dikeluarkannya empat undang-undang di atas adalah memberikan power kepada Pemerintahan Howard untuk mengambil tindakan lebih lanjut yang dikenal dengan Pacific Solution dan Temporary Protection Visa (TPV).

\subsubsection{Pacific Solution}

Kebijakan luar negeri ini dikeluarkan oleh Howard yang menerangkan bahwa para pencari suaka di atas kapal yang tidak sah - Irregular Maritime Arrivals - dapat dicegat (biasanya oleh angkatan laut Australia) dan dipindahkan ke pusat pemrosesan lepas pantai di Pulau Nauru dan Manus di Papua Nugini. Pengaturan ini adalah hasil dari serangkaian negosiasi Australia dengan berbagai pemerintah termasuk Timor Timur, Kiribati, Fiji, Palau, Tuvalu, Tonga dan Prancis-terkait dengan Polinesia Prancis (Phillips 2012; Taylor 2005). Kebijakan ini juga mencakup penahanan kapal dan penahanan imigran ilegal (detention) sebelum mereka memasuki daerah lepas pantai Australia dan untuk me-resettle atau mengakomodasi mereka yang telah dikonfirmasi sebagai pengungsi (Sd et al., 2018). Rajaram (2003:2) mendefinisikan Pacific Solution sebagai "a component of ongoing state formation, securitisation and consecration through the strengthening of Australian "place" and the consequent derogation of other "placements". Definisi ini jelas menunjukkan bahwa Australia sedang mencoba untuk memperkuat identitas kedaulatannya melalui elemen pembentukan negara, sekuritisasi dan konsekrasi pada masa pemerintahan Howard. Namun, Magner (2004) dan Mansted (2007) menilai kebijakan ini telah melanggar Konvensi Pengungsi dan prinsip non-refoulement; secara khusus kebijakan penahanan yang diterapkan juga tidak sesuai dengan kewajiban hukum internasional serta spirit dari Konvensi pengungsi yang telah Australia tandatangani.

\section{Gambar 1. Posisi Australia dalam Pemetaan Pacific Solution}

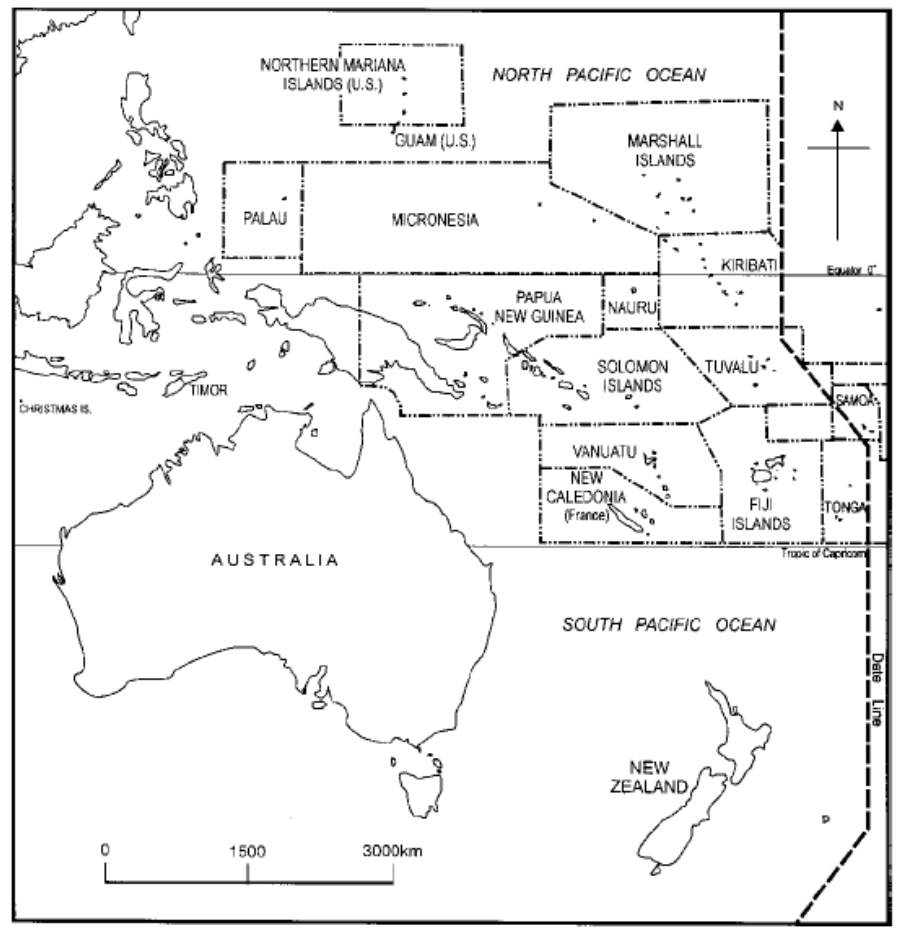

Sumber: (Rajaram 2003, 291)

\subsubsection{Temporary Protection Visa (TPV)}


Visa Perlindungan Sementara (TPV) secara resmi diperkenalkan oleh Pemerintahan John Howard pada Oktober 1999 untuk merespon kepada para imigran ilegal. Namun, jenis visa ini (temporary humanitarian protection visas) telah diperkenalkan sebelumnya oleh pemerintahan Bob Hawke ketika merespon pembantaian siswa di Tiananmen Square pada tahun 1989 (Mansouri dan Leach 2009, 102). Visa perlindungan sementara diberikan kepada pencari suaka yang membutuhkan perlindungan sebagai pengganti visa perlindungan permanen. Selama pemerintahan Howard, pemegang TPV menghadapi banyak ketidakuntungan dan ketidakpastian terkait kehidupan mereka seperti mereka tidak memiliki hak untuk melamar reuni keluarga dengan pasangan dan anak-anak yang berada di luar negeri; tidak mendapat akses Centrelink (lembaga negara yang memberikan subsidi); tidak mendapat hak untuk belajar bahasa Inggris; dan tidak memiliki akses terhadap akomodasi darurat dan perumahan negara. Meskipun TPV diperkenalkan oleh Howard tahun 1999, visa ini kemudian dihilangkan pada tahun 2008 oleh pemerintahan Kevin Rudd, dan diperkenalkan kembali lagi pada Oktober 2013 oleh Pemerintahan Tony Abbott (Asylum Seeker Resource Center 2013).

\subsection{Kebijakan Luar Negeri Howard berdasarkan 'a logically tripartite approach'}

Seperti yang dijelaskan sebelumnya, ada tiga dimensi dalam pengambilan aksi kebijakan luar negeri menurut Carlnaes. Ketiga dimensi ini memiliki hubungan sebab-akibat dan saling memengaruhi antara satu dan yang lain. Pertama adalah Intentional Dimension (choice dan preference). Pada dimensi ini, Carlsnaes (1992:254) mengatakan '...one can choose to 'deepen' the analysis by providing a causal determination...' Artinya bahwa kita dapat memahami kebijakan luar negeri yang diadopsi Howard terhadap imigran ilegal dengan membuat deskripsi alasan atau penyebabnya. Ada beberapa alasan yang telah disebut pada pembahasan sebelumnya, seperti Howard tidak ingin dunia melihat Australia sebagai negara yang terlalu mudah untuk dimasuki oleh imigran, dan berusaha untuk menjaga kepentingan nasional serta kedaulatan Australia dengan membatasi jumlah imigran yang datang secara ilegal. Pilihan dan preferensi ini secara tidak langsung menjelaskan bahwa Howard ingin menunjukkan kewibawaannya sebagai seorang patriot dan memastikan keamanan negara serta warganya meskipun mendapat kritikan dari berbagai pihak. Seperti yang diamati oleh McDonald, dikutip dalam Gleeson (2016:196) ... "the approach of Howard and his government was to sideline critics by insinuating that they held a lack of concern about Australian security and Australians generally". Pendekatan Howard ini juga diperkuat dengan peristiwa yang membahayakan warga Australia termasuk peristiwa Bom Bali.

Dimensi kedua adalah Dispositional. Untuk memahami rasionalitas dimensi ini, Carlsnaes (1992:265) memberikan contoh aplikasi Swedia untuk keanggotaan European Community (EC) di mana nilai (values) dan persepsi (perceptions) dapat menginformasikan kausal perilaku disengaja pembuat keputusan, seperti keinginan kuat Swedia untuk berpartisipasi lebih penuh dalam pemulihan ekonomi dan dinamisme Eropa Barat. Dalam konteks Pemerintahan Howard, sangat jelas bahwa ia menggunakan isu imigran ilegal untuk meningkatkan popularitasnya sebagai seorang pemimpin khususnya untuk menang dalam election. McKay et al., (2017:3) mengamati bahwa isu asylum-seekers mendapat perhatian yang lebih signifikan pada pemilu federal tahun 2001 daripada pemilihan tahun-tahun sebelumnya di Australia. Oleh karena itu, Howard memanfaatkan momen tersebut. Seperti dalam salah satu pidato kampanyenya, Howard mengatakan, "We will decide who comes to this country, and the circumstances in which they come"'(Stats 2015, 1). Dalam konteks ini, Howard tidak hanya menarik perhatian masyarakat tapi juga membentuk persepsi publik 
terhadap tindakannya yang mengedepankan keterlibatan komunitas Australia dalam penentuan kebijakan. Dalam kampanye, Howard dan tim pendukungnya juga tidak menggunakan kata-kata diskriminasi yang merujuk pada etnis atau agama tertentu, melainkan menggunakan kata 'ilegal' seperti yang digambarkan pada kasus Tampa (Mcculloch 2004).

\section{Gambar 2. Penjelasan pengambilan kebijakan luar negeri}

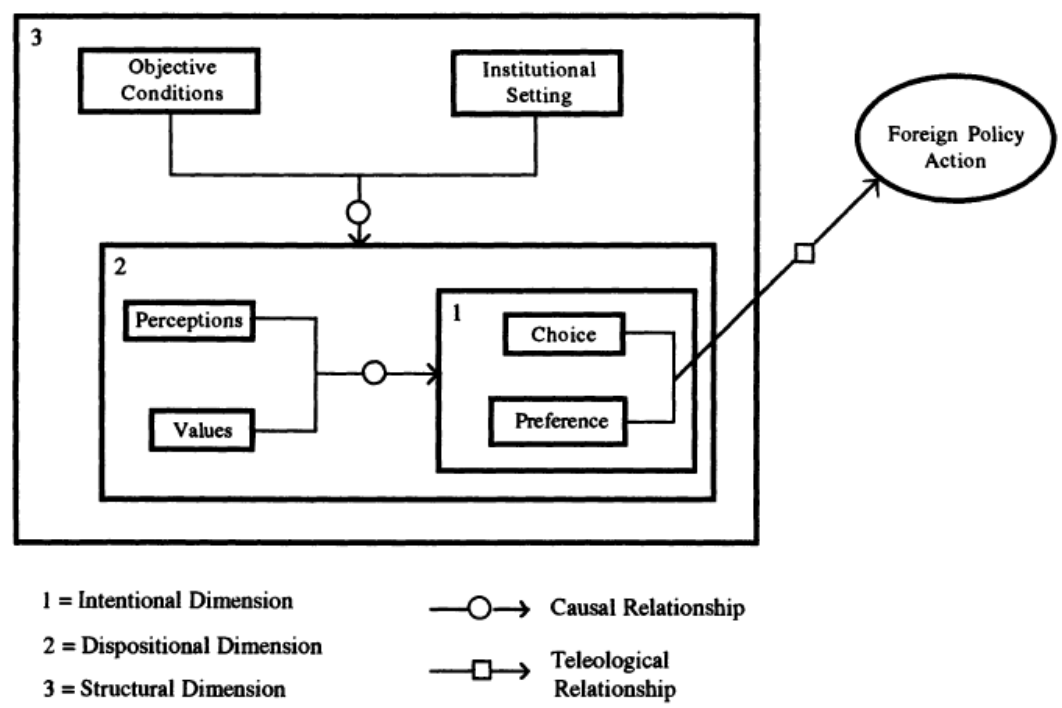

Sumber: (Carlsnaes 1992, 254)

Carlsnaes (1992:265) selanjutnya menjelaskan bahwa faktor-faktor yang muncul dari dimensi pertama dan kedua kemudian dapat dielaborasi untuk memahami dimensi ketigastructural yang terdiri atas kondisi objektif (objective conditions) dan pengaturan kelembagaan (institutional setting) - dalam kaitannya dengan pembuatan kebijakan luar negeri. Dengan masih menggunakan contoh aplikasi Swedia untuk keanggotaan EU, Carlsnaes memberikan ilustrasi seperti ketergantungan ekonomi Swedia pada perdagangan dengan anggota Komisi Eropa, kelancaran aturan dan praktik yang menjadi ciri rezim netralitas pasca-Perang Dingin, penataan kembali pengelompokan domestik yang strategis, dan lainnya. Dalam konteks Australia, unsur pengaturan kelembagaan jelas terlihat pada keempat Undang-Undang baru/amandemen yang dikeluarkan oleh pemerintahan Howard dalam membentuk kebijakan luar negerinya yaitu Borders Protection (Validation and Enforcement Powers) Act, 2001 (BPB Act); Migration Legislation Amendment Act No 6. 2001 (MLA Act); Migration Amendment (Excision from migration zone) Act, 2001 (MAB Act); Migration Amendment (Excision from migration zone) (Consequential Provision) Act 2001 (MAB II Act). Selain itu, kondisi obyektif pada dimensi structural ini juga terlihat di mana sebagai seorang pemimpin, Howard memiliki power untuk mengontrol negaranya dan sebagai seorang petahana dalam pemerintahan untuk mempertahankan status quo. Memang benar, John Howard (1996-2007) adalah Perdana Menteri Australia terlama kedua setelah Sir Robert Menzies (1949-1966).

\section{Kesimpulan}

Tulisan ini telah melihat kebijakan-kebijakan yang dikeluarkan oleh Perdana Menteri John Howard dalam merespon imigran ilegal yang menggunakan kapal menuju Australia. Meskipun kebijakan-kebijakan Howard dapat dikatakan sebagai inovasi baru Australia dalam 
merespon imigran ilegal, komunitas internasional ternyata tidak memberikan respon yang positif seperti yang disampaikan oleh Komisaris HAM PBB dan UNHCR. Kebijakan luar negeri Howard dinilai bertentangan dengan Konvensi 1951 dan Teks Protokol 1967 Mengenai Status Pengungsi yang telah ditandatangani negeri kanguru tersebut. Kebijakan Howard juga dinilai merugikan Australia dalam menjalin kerja sama dengan negara lain seperti pada kasus Tampa (Norwegia). Pemerintahan Howard ketika itu diharapkan dapat menerima para imigran ilegal (pencari suaka), termasuk dalam kasus Tampa, selayaknya diamanatkan dalam regulasi internasional yang telah disepakati oleh Australia.

Dengan menggunakan analisis 'a logically tripartite approach' yang ditawarkan oleh Carlsnaes, penulis menemukan bahwa Kebijakan Howard dalam merespon imigran ilegal tidak hanya bersifat state-centric yang berfokus pada perlindungan kedaulatan negara; tetapi juga memiliki motivasi untuk mempertahankan kekuasaan (power control). Pertama, Howard ingin menunjukkan pada dunia bahwa ia adalah pemimpin yang berbeda dari sebelumnya dengan menegaskan bahwa Australia tidak dapat diremehkan sebagai negara yang dapat dicapai dengan sesuka hati. Kedua, Howard ingin menunjukkan bahwa pembatasan jumlah imigran ilegal adalah termasuk ranah kepentingan nasional untuk melindungi komunitas Australia. Ketiga, Howard menunjukkan bahwa kebijakannya terkait imigran ilegal dapat memengaruhi nuansa perpolitikan di Australia khususnya pada pemilihan umum di tingkat federal. Keempat, Howard menunjukkan kemampuannya dalam konteks pengelolaan kelembagaan dengan mengeluarkan Undang-Undang baru/amandemen untuk memperkuat kebijakan luar negerinya. Hasil temuan pada artikel ini tentunya dapat menjadi referensi bagi penelitian-penelitian dengan pendekatan berbeda dimasa mendatang namun merujuk pada topik kajian yang sama. 


\section{DAFTAR PUSTAKA}

\section{Buku}

Cecilia, Menjívar., Marie, Ruiz, \& Immanuel, Ness. 2019. The Oxford Handbook of Migration Crises. New York: Oxford University Press.

Gleeson, Kathleen. 2016. Australia's “war on Terror” Discourse. New York: Routledge.

Holsti, K.J. 1992. International Politics: A Framework for Analysis. New Jersey: Prentice Hall.

Kelly, Paul. 2009. The March of Patriots: The Struggle for Modern Australia. Melbourne: Melbourne University Press.

\section{Jurnal}

Azis, Avyanthi. 2014. "Menelaah Konsep Human Security : Studi Kasus Penanganan Masalah Pengungsi Afganistan di Australia (1999-2002)." Global 7(1): 80-105

Carlsnaes, Walter. 1992. "The Agency-Structure Problem in Foreign Policy Analysis." International Studies Quarterly 36 (3): 245. https://doi.org/10.2307/2600772.

Creek, Tristan G. 2014. "Starving for freedom: an exploration of Australian government policies, human rights obligations and righting the wrong for those seeking asylum." The International Journal of Human Rights 18 (4-5): 479-507. https://doi.org/https://doi.org/10.1080/13642987.2014.901967.

Fox, Peter D. 2010. "International Asylum and Boat People: The Tampa Affair and Australia's 'Pacific Solution."” Maryland Journal of International Law 25 (1): 356-74.

Magner, Tara. 2004. "A Less than 'Pacific' Solution for Asylum Seekers in Australia." International Journal of Refugee Law 16 (1): 53-90. https://doi.org/10.1093/ijrl/16.1.53.

Mansouri, Fethi, and Michael Leach. 2009. "The Evolution of the Temporary Protection Visa Regime in Australia." International Migration 47 (2): 101-26. https://doi.org/10.1111/j.1468-2435.2008.00483.x.

Mansted, Rachel. 2007. "Bond University Student Law Review The Pacific Solution Assessing Australia's Compliance with International Law The Pacific Solution Assessing Australia's Compliance with International Law THE PACIFIC SOLUTION ASSESSING AUSTRALIA'S COMPLIANCE WITH I." Bond University Student Law Review 3 (1). http://epublications.bond.edu.au/buslr/vol3/iss1/1.

Mcculloch, Jude. 2004. "NATIONAL (IN)SECURITY POLITICS IN AUSTRALIA Fear and the Federal Election." Alternative Law Journal 29 (2). http://www.austlii.edu.au/au/journals/AltLawJ1/2004/19.html.

McKay, Fiona H., Lucy Hall, and Kehla Lippi. 2017. "Compassionate Deterrence: A Howard Government Legacy." Politics and Policy $45 \quad$ (2): 169-93. https://doi.org/10.1111/polp.12198.

Philpott, Simon. 2002. "Protecting the Borderline and Minding the Bottom Line: Asylum Seekers and Politics in Contemporary Australia." Refuge - Canada's Periodical on Refugees (Toronto) 20 (4): 63-75.

Prabaningtyas, Rizka Fiani. 2015. "The Impact of Australian Policy on Illegal Maritime Arrivals ( Ima ) Towards Current Relation of Australia-Indonesia." Jurnal Penelitian Politik 12: 69-81.

Rajaram, Prem Kumar. 2003. “ MAKING PLACE ': THE 'PACIFIC SOLUTION' AND AUSTRALIAN EMPLACEMENT IN THE PACIFIC Prem Kumar Rajaram” 24 (3): 290-306.

Riyanto, Sigit. 2010. "Prinsip Non-Refoulement Dan Relevansinya Dalam Sistem Hukum Internasional." Mimbar Hukum 22 (3): 434-49. https://doi.org/10.22146/jmh.271. 
Taylor, Savitri. 2005. "The Pacific Solution or A Pacific Nightmare: The Difference Between Burden Shifting and Responsibility Sharing." Asian-Pacific Law and Policy Journal 6 (1): 1-43.

\section{Website}

Encyclopaedia $\quad$ Britannica. $2020 . \quad$ "Foreign Policy." In . https://www.britannica.com/topic/evidence-based-policy.

Government, Australian. 2001. "Border Protection (Validation and Enforcement Powers) Act 2001.” 2001. https://www.legislation.gov.au/Details/C2004A00886.

Spooner, Dy dan Hancocok, Nathan 2001. "Migration Amendment (Excision from Migration Zone) (Consequential Provisions) Bill 2001." https://www.aph.gov.au/Parliamentary_Business/Bills_Legislation/bd/bd0102/02bd070.

Phillips, Janet. 2012. "The 'Pacific Solution'revisited: A Statistical Guide to the Asylum Seeker Caseloads on Nauru and Manus Island." Parliament of Australia, Department of Parliamentary.. https://www.aph.gov.au/About_Parliament/Parliamentary_Departments/Parliamentary_L ibrary/pubs/BN/2012-2013/PacificSolution.

Pipes, Daniel. 2001. "[Australia's] Crisis of Illegal Immigration," 2001. http://www.danielpipes.org/50/australias-crisis-of-illegal-immigration.

Villar, Katrine Del. 2001. "Migration Legislation Amendment Bill (No 6) 2001." https://www.aph.gov.au/Parliamentary_Business/Bills_Legislation/bd/bd0102/02bd055.

\section{Sumber lainnya}

Asylum Seeker Resource Center. 2013. "Temporary Protection Visas." Asylum Seeker Resource Center, October: 1-2.

Coombs, Moira. 2004. "Excisions from the Migration Zone-Policy and Practice," 4-5.

Nurcahyawan, Teddy, and Stefanus Reynold Andika. 2017. "PERMINTAAN MAAF AUSTRALIA DAN PRINSIP NON REFOULEMENT (STUDI KASUS PENCARI SUAKA SRI LANKA) Teddy Nurcahyawan" 2 (1).

Puteri C. M. A. S. 2011. "“KEBIJAKAN LUAR NEGERI AUSTRALIA TERHADAP INDONESIA: PEMERINTAHAN JOHN HOWARD DARI PARTAI KOALISI LIBERAL (1996-2007) DAN PEMERINTAHAN KEVIN RUDD DARI PARTAI BURUH (2007-2010." Universitas Islam Negeri Syarif Hidayatullah Jakarta. 103.229.202.68.

Sd, Hardi Alunaza, Ireng Maulana, and Adityo Darmawan Sudagung. 2018. "THE PACIFIC SOLUTION AS AUSTRALIA' S POLICY TOWA RDS ASYLUM SEEKER AND IRREGULAR MARITIME ARRIVALS ( IMAS ) IN THE JOHN HOWARD ERA," 61-75.

Septa, Albert Alfa. 2018. "Ancaman Keamanan Australia Pada Masa Pemerintahan John Howard : 2001-2007," no. 2005: 2001-7.

Stats, Katrina. 2015. "We Will Decide: Refugee and Asylum Policy During the Howard Era Before Tampa.” Australian Studies 7 (January 2015). 